CASE REPORT

\title{
Endocarditis due to Aortic Root Abscess in a Patient with Rupture of Sinus of Valsalva
}

\author{
Arif Maqsood Ali ${ }^{1}$, Gule Rana Waseem², Shazia Arif ${ }^{3}$ \\ ${ }^{1}$ Department of Pathology and Blood Bank, Rawalpindi Institute of Cardiology, Pakistan \\ ${ }^{2}$ Rawalpindi Institute of Cardiology, Rawalpindi, Pakistan \\ ${ }^{3}$ Army Medical Corps, Pakistan
}

\begin{abstract}
A ruptured sinus of Valsalva aneurysm rarely accompanies the aortic valve endocarditis. A 40-year old female presented with low threshold exertional dyspnea and fever. Transthoracic and transesophageal echocardiography showed ruptured sinus of Valsalva aneurysm in right ventricle with multiple vegetation at the aortic root. Initial blood cultures were negative and an empirical antibiotic therapy was started. Patient was operated for surgical repair of sinus of Valsalva aneurysm. An aortic root abscess with rupture of sinus of Valsalva was found at operation. However, postoperatively she developed sepsis and multiorgan failure leading to her death. J Microbiol Infect Dis 2018; 8(2):69-72
\end{abstract}

Keywords: Aortic aneurysm, aortic rupture, sinus of Valsalva, infective endocarditis, aortic abscess, transesophageal echocardiography

\section{INTRODUCTION}

A sinus of Valsalva aneurysm (SOVA) is an enlargement of the aortic root area between the aortic valve annulus and the sinotubular ridge. In a normal heart, both the left and right sinus contains their respective coronary artery ostia, whereas the posterior sinus is a non-coronary sinus [1].

SOVA is a congenital or acquired cardiac defect which is found in roughly $0.09 \%$ of the general population [2]. Less commonly, it is associated with endocarditis, atherosclerosis, trauma, syphilis, or aortic dissection. It's incidence is five times higher in Asian countries with male/female ratio as $4: 1[2,3]$.

The anatomic setting of a SOVA usually predicts the clinical outcome of aneurysm rupture. Rupture of the right and non-coronary sinuses typically results in communication between the aorta and the right ventricular outflow tract or the aorta and the right atrium. Symptoms include substernal chest pain, abdominal pain and mild to severe dyspnea. In many cases, patients may experience symptoms of acute heart failure, cardiac tamponade, hemodynamic instability and even cardiac death [4]. Diagnosis is confirmed by transesophageal echocardiography or catheterization [5].

Endocarditis (IE) can complicate rupture of sinus of Valsalva \& vice versa [6-8]. Aortic root abscess is the most severe sequela of infective endocarditis and its surgical management is a complicated procedure because of the high risk of morbidity and death [9]. SOVA with aortic root abscess has rarely been reported.

\section{CASE REPORT}

A 40-year old normotensive and normoglycemic women presented in emergency department of a tertiary care cardiac hospital in Rawalpindi, Pakistan on May $23^{\text {rd }}$ 2017. She complained of shortness of breath, fever and pain in right hypochondrium for last 15 days. Her past history was insignificant. On clinical examination, she was anemic, febrile and looked lethargic. She had a temperature of $101{ }^{\circ} \mathrm{F}$, pulse rate of $101 /$ minute and respiratory rate of 30 /minute. Her jugular venous pressure was raised with prominent right sided facial veins. A loud continuous sawing murmur was heard throughout the first and second heart sounds. ECG showed sinus tachycardia. Arterial blood

Correspondence: Dr. Arif Maqsood Ali, Department of Pathology \& Blood Bank, Rawalpindi Institute of Cardiology, Rawalpindi, Punjab, Pakistan

E-mail: drarifmaqsoodali@hotmail.com

Received: 28 September 2017 Accepted: 20 Mai 2018

Copyright (C JMID / Journal of Microbiology and Infectious Diseases 2018, All rights reserved 
gas analysis revealed oxygen desaturation. Laboratory investigations showed hemoglobin (Hb) $7.1 \mathrm{~g} / \mathrm{dl}$, white cell count (WBC) count of $16.1 \times 10^{9} / \mathrm{l}$ with normal hepatic and renal profile. Mantoux test, Antinucleur Antibody and VDRL were negative. Chest X-Ray showed markedly dilated right vena caval shadow. Initial blood culture did not yield any growth. Transthoracic and Transesophageal echocardiography showed aneurysmal tissue of aortic root with small multiple vegetations $2-3 \mathrm{~mm}$ in size. Intravenous antibiotics for culture negative endocarditis were started which included intravenous injectable Ceftriaxone $1 \mathrm{~g}$ every 12 hourly, injectable Vancomycin 500 mg every 12 hourly and injectable Levofloxacin $500 \mathrm{mg}$ once daily. At operation, there was rupture of sinus of Valsalva aneurysm with small aortic root abscess at its base. The aortic root abscess was excised and necrotic tissue was removed. Reconstruction of aortic root was done with bovine pericardial patch.

Postoperatively, the patient condition deteriorated and she could not be weaned off from ventilator. Her repeat complete picture showed Hb $10 \mathrm{~g} / \mathrm{dl}$, WBCs count $18.9 \times 10 / \mathrm{L}$ and platelet count $23 \times 10^{12} / \mathrm{ul}$. Complement Reactive Protein (CRP) was $114 \mathrm{~g} / \mathrm{dl}$. Her liver \& renal biochemical profile showed Alanine Aminotransferase (ALT) $259 \mathrm{U} / \mathrm{l}$, Alkaline phosphatase (ALP) $278 \mathrm{U} / \mathrm{l}$, Urea $190 \mathrm{mmol} / \mathrm{l}$, Creatinine $2.3 \mathrm{mg} / \mathrm{dl}$. D dimers were more than $200 \mathrm{ng} / \mathrm{ml}$. Blood culture yielded growth of Escherichia coli sensitive to Piperacillin/ Tazobactem and resistant to all other antibiotics. Piperacillin/Tazobactem 3.75 g i.v. 8 hourly was started. However, she went into cardiopulmonary arrest. She was resuscitated but could not be revived.

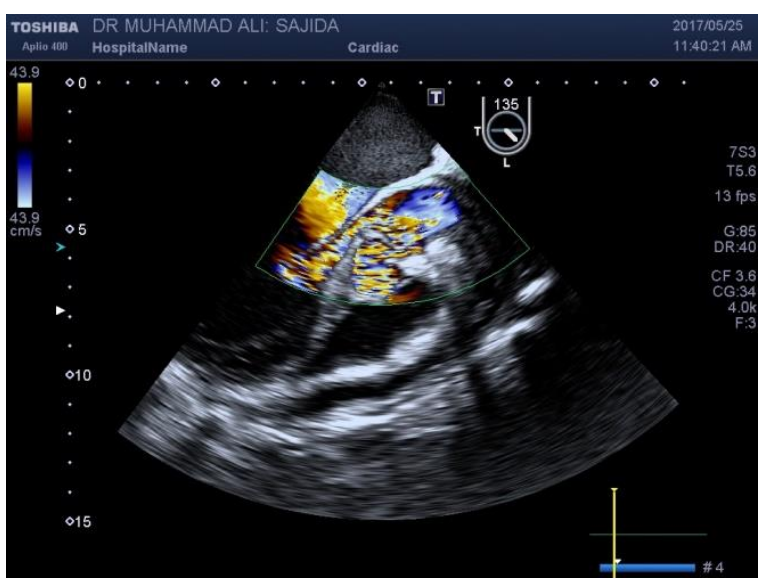

Figure 1. Transoesophageal Echocardiography showing in colour M mode ruptured sinus of Valsalva into right ventricle.

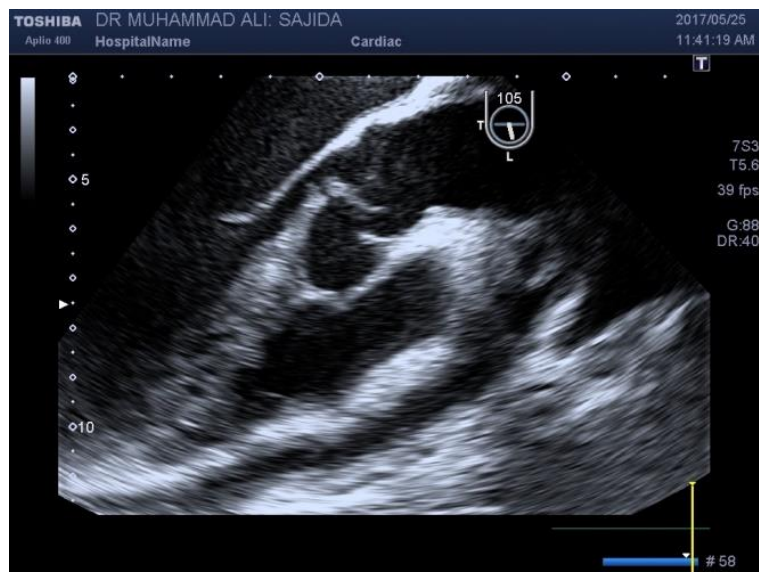

Figure 2. Transoesophageal echocardiography 2 D image showing flow from sinus of Valsalva into right ventricle and small vegetations.

\section{DISCUSSION}

Sinus of Valsalva aneurysm (SOVA) is a rare disorder. It is usually congenital, but other origins have been described. It may be asymptomatic or it may present as angina or with symptoms of valvular insufficiency or outflow obstruction [5]. It can become complicated with rupture or infection $[6-8,10]$ Rupture of a SOVA occurs most commonly at the right ventricle $(60 \%)$, right atrium $(29 \%)$, followed by the left atrium (6\%), left ventricle $(4 \%)$ and at pericardium $(1 \%)[11,12]$. Incidence of ruptured SOVA is $0.46 \%-3.5 \%$ and $0.14 \%$ $0.23 \%$ in Eastern and Western countries respectively. Its incidence is five times higher in Asian population with male/female ratio as $4: 1$ [3]. The unruptured SOVA often remains undiagnosed but may manifest with symptoms of right ventricular outflow obstruction [13].

Once ruptured, SOVA often leads to hemodynamic instability. Transesophageal echocardiography or catheterization are required to confirm the diagnosis [5].

Infective endocarditis has been reported in patients with ruptured SOVA. Both bacterial endocarditis leading to rupture of sinus of Valsalva and sinus of Valsalva rupture leading to infective endocarditis have been cited in literature [6,7]. However, SOVA with aortic root abscess has rarely been reported. In our patient, there was ruptured sinus of Valsalva aneurysm and a small aortic root abscess with small multiple vegetations $2-3 \mathrm{~mm}$ in size. The prognosis of infective endocarditis depends upon whether the infected valve is native or prosthetic [14]. The type and virulence of the microorganism and resistance of the host are important in determining the fate of IE, it's 
complications like paravalvular abscess, cardiac fistulas and severe destruction of the native aortic valve. A mechanical valve is often infected in its sewing ring and the infection also extends into surrounding structures [9]. The microbiology of the IE also depends on the nature of valve i.e. native or prosthetic. Native-valve endocarditis causing perianular abscess involves aortic valve more often than mitral valve [15].

An uncontrolled aortic root abscess is often complicated by a burrowing abscess, a cardiac fistula or a rupture into a cardiac chamber, a pseudoaneurysm, or an arrhythmia that can lead to hemodynamic instability. Early and extensive surgical resection of aortic root abscess followed by its reconstruction can be lifesaving as antibiotics alone are usually ineffective to stop the destruction of cardiac tissue by the abscess [9].

In our study, the presence of sepsis, multi-organ failure and coagulopathy lead to the fatal outcome of the case. A large, multicenter, international study showed that $22 \%$ of patients with aortic valve IE had perianular abscess which was more frequent in prosthetic valves than with native valves ( $40 \%$ vs $19 \%$ ) [16].

SOVA complicated with endocarditis or sepsis has 4-5 times greater risk of perioperative death [13]. The operative mortality rate for the surgical treatment of aortic root abscess varies from $3.9 \%$ to $25 \%$ [16]. Early intervention for IE with extended sequelae is known to have better outcome. Surgeons therefore opt for an early operation if life-threatening sequelae do not develop [17 Majority of urgent surgical series have high mortality rates, ranging from $55 \%$ to $77 \%[14]$.

\section{CONCLUSION}

Although rupture of sinus of Valsalva is a rare condition in young to middle aged patients. It can be life threatening condition due to hemodynamic instability and can lead to acute heart failure or sudden death. Bacterial endocarditis and aortic root abscess can complete SOVA which should be confirmed by transesophageal echocardiography or cardiac catheterization. Urgent Surgical repair and appropriate antibiotic therapy should be considered to decrease morbidity and mortality due to the disease and its complications.

\section{ACKNOWLEDGMENTS}

Financial Support: None declared.

Conflict of interest: None declared.

\section{REFERENCES}

1) Bricker $A O$, Avutu B, Mohammed TL, et al. Valsalva sinus aneurysms: findings at CT and MR imaging. Radiographics 2010; 30:99-110.

2) Weinreich M, Yu P-J, Trost B. Sinus of Valsalva aneurysms: review of the literature and an update on management. Clinical Cardiology 2015; 38 (3):185189.

3) Chu SH, Hung CR, How SS, et al. Ruptured aneurysms of the sinus of Valsalva in oriental patients. J Thorac Cardiovasc Surg 1990; 99: 288298.

4) Feldman DN, Roman MJ. Aneurysms of the sinuses of Valsalva. Cardiology 2006; 106:73-81.

5) Miranda D, Peter AA, Osorio J, Ferreira AC. Ruptured aneurysm of the noncoronary sinus of Valsalva. Tex Heart Inst J 2005; 32:586-588.

6) Vereckei A, Vándor L, Halász J, et al. Infective endocarditis resulting in rupture of sinus of Valsalva with a rupture site communicating with both the right atrium and right ventricle. J Am Soc Echocardiogr 2004; 17:995-997.

7) Encarnacion CO, Loranger AM, Bharat Kumar AG, et al. Bacterial Endocarditis caused by Lactobacillus acidophilus Leading to Rupture of Sinus of Valsalva Aneurysm. Tex Heart Inst J 2016; 43:161-164.

8) Ikeda A, Nakajima T, Konishi $T$, et al. Infective endocarditis of an aorto-right atrial fistula caused by asymptomatic rupture of a sinus of Valsalva aneurysm: a case report. Surg Case Rep 2016; 2:43 .

9) Kirali K, Sarikaya S, Ozen Y, et al. Surgery for Aortic Root Abscess: A 15-Year Experience. Tex Heart Institute J 2016; 43:20-28. doi:10.14503/THIJ14-4747.

10) Patra KP, VanchiereJA, Bocchini JA Jr, et al. Endocarditus with rupture sinus of Valsalva aneurysm caused by non vaccine streptococcal pneumonia serotype 21. Tex Heart Institute J 2012; 39:277-280.

11) Vautrin E, Barone-Rochette G, Philippe J. Rupture of right sinus of Valsalva into right atrium: Ultrasound, magnetic resonance, angiography and surgical imaging. Arch Cardiovasc Dis 2008; 101:501-502.

12) Missault L, Callens B, Taeymans $Y$. Echocardiography of sinus of Valsalva aneurysm with rupture into the right atrium. Int $\mathrm{J}$ Cardiol 1995; 47: 269-272.

13) Kutiyal AS, Daga MK. Ruptured Sinus of Valsalva with Infective Endocarditis Complicated with PostInfectious Acute Glomerulonephritis: A Rare Case Presentation. J Clin Diag Res 2016; 10 (10):OD14.

14) David TE, Regesta T, Gavra G, Armstrong S, Maganti MD. Surgical treatment of paravalvular abscess: long-term results. Eur J Cardiothorac Surg 2007; 31(1):43-48. 
15) Kirali K, Guler M, Yakut N, et al. Combined medical and surgical treatment for active native valve infective endocarditis: ten-year experience. Turk Kardiyol Dern Ars 2001; 29 (9):543-548.

16) Anguera I, Miro JM, Cabell $\mathrm{CH}$, et al. Clinical characteristics and outcome of aortic endocarditis with periannular abscess in the International Collaboration on Endocarditis Merged Database. Am J Cardiol 2005; 96 (7):976-981.

17) Murdoch DR, Corey GR, Hoen B, et al. Clinical presentation, etiology, and outcome of infective endocarditis in the $21^{\text {st }}$ century: the International Collaboration on Endocarditis-Prospective Cohort Study. Arch Intern Med 2009; 169 (5):463-473. 